\title{
The Influence of Professional Innovation Competition on the Cultivation of Innovative Talents in Colleges and Universities-Inspired by the National College Students' Tea Skills Competition
}

\author{
Ping Chen \\ College of Horticulture, Fujian Agriculture and Forestry \\ University \\ Fuzhou 350002
}

\author{
Lingjuan Ye \\ Dean's Office, Fujian Agriculture and Forestry University, \\ Fuzhou 350002
}

\begin{abstract}
The Professional innovation competition in colleges and universities acts as one of the connotation indexes of "double first-class" in colleges and universities, and the "professional innovation competition" is a professional competition which based on the subject, the professional practical training platform, and enjoying great innovative connotation. This paper, taking "National Tea Art Skill Competition" as the starting point, aims to enhance the innovation consciousness and innovation ability of college students, at the same time, conducts an in-depth discussion on invisible knowledge, external specialized skill, and the promotion of employment conversion rate of this major.
\end{abstract}

Keywords-Innovation; Talent training; Professional competition

\section{THE STATUS OF INNOVATIVE TALENT CULTIVATION MODEL IN CHINA}

"The key to our party being able to go through the test and suffering is to continue to carry out practical innovation and theoretical innovation," Xi J.P.said. Innovation is the soul of national progress, innovation ability is the core of national development competitiveness, talent competition is essentially the competition of innovation ability [1]. The education sector is recognized that innovative education is a future-oriented educational, is the key to the future development of the nation and the country, with the increasingly fierce international competition, independent innovation and innovative talents are increasingly becoming the core focus of competition between countries. Based on this, it is urgent to improve the innovation ability of universities and speed up the cultivation of innovative talents with high quality.

In the age of Internet + , innovation and entrepreneurship education are regarded as having equal emphasis on education [2]. Innovation education is different from entrepreneurship education, and innovation education focuses on the cultivation of college students ' innovative spirit, innovative consciousness, innovative thought and innovation ability [3], not necessarily "to the way of entrepreneurs". Innovation education is different from traditional education, it is based on the cultivation of people's all-round development, but more emphasis on

Subject Source: the "13th Five-Year" Plan of Education Science in Fujian Province in 2018:A Comparative study on the Reform of Sino-American

General Education in the era of knowledge economy (2018CG02122). innovation, knowledge collision, the relevance of economic development and social needs to adapt to the advent of knowledge economy and information age.

In the existing domestic innovation education can be summed up into three models: (1) Innovation combined with practice. Pay attention to the integration of theoretical learning and practical exercise, through the grass-roots, frontline to carry out social service work. (2) Innovation in combination with the profession. Through the skills competition to promote the national institutions and similar disciplines in the same platform competition and display, in order to enhance college students ' scientific research interests, innovative awareness and practical ability. (3) Innovation oriented to social needs and enterprise demand, through the deep integration with enterprises and industries, scientific research, practice and innovation organically combined.

These three models are currently the most common innovative talent training models in various colleges and universities. Many colleges and universities launch a combination of enterprise and market demand of practical projects and product development projects, through a variety of innovative creative competitions, so that college students can enter the university as soon as possible to establish innovative creative awareness and take the initiative to join scientific research training.

Among them, agriculture and forestry related to tea colleges and universities combined with tea professional characteristics, from the first time in 2009 to hold the National college students Tea Skills competition has been three, covering the country's 29 agroforestry institutions, a total of more than 1000 contestants and instructors to participate. The National college students Tea Skills competition, with the theme of "Promoting traditional culture, strengthening exchanges and cooperation and cultivating innovative talents", aims to enhance college students ' professional learning and practical ability through such projects as tea mat design, personal innovation tea art and Innovation team competition, which has been used as a means to promote and disseminate China's excellent traditional tea culture, show the innovative 
ability An important carrier of professional skills and comprehensive quality. The holding of the competition aroused the interest of college students in tea culture, and at the same time improved the cultural accomplishment and inner temperament of college students. The talent model of the National college students 'tea skills competition is a kind of personnel training mode which combines professional theory with practical skills, promotes the transformation of college students ' practice and the transformation of professional skills through fierce skill competition and creative competition, and promotes the professional conversion rate of college students majoring in tea science after graduation.

\section{THE CONNOTATION OF PROFESSIONAL INNOVATION COMPETITION}

What is "Professional Innovation Competition"? First of all, the emphasis on a "creation" can be understood as "innovation", "creativity", emphasis on the spirit of pioneering [4], "none" in the students "have", "have" in the selection of "excellent"; The second form is "competition", "competition to promote learning, competition to promote innovation, through competition to catalyze the internalization of college students' professional knowledge and skills during school[5]. Third, take root in the profession, pay close attention to the professional developments, and use the latest professional developments and technological developments as the basis of the innovative competition [6]. Therefore, "professional innovation competition" can be defined as the specialty with innovative connotation based on the subject and professional training platform. Competition.

The competition of professional innovation in colleges and universities is one of the connotations of "double first-class" in colleges and universities. Promoting the competition of professional innovation can not only enhance the creative consciousness and ability of college students. Through professional innovation competition, contestants compete with students from all over the world, domestic and foreign colleges and universities, overseas (tea) students to show themselves, stimulate the pursuit of science, the pursuit of truth innovative spirit [7].

\section{TO EXPLORE THE TRAINING MODE OF INNOVATIVE TALENTS WITH PROFESSIONAL INNOVATION SKILL COMPETITION AS THE CARRIER}

At present, the national professional skill competition forms a blowout trend, and colleges and universities have gradually realized that it is a very useful and effective model to construct a competitive platform for college students to promote the combination of professional learning and professional practice. In addition to the National College Students Tea Skill Competition, there are also Food Processing Creative Competition, College Students Electronic Design Competition, National Sand Table Design Competition, National University Landscape Design Graduation Work Exhibition, National Young Students Interior Design Competition, etc.[8]. There are a wide variety of open competitions across the country, covering a wide range of industries and disciplines, providing opportunities for college students to compete and exercise, while at the same time offering a specialist The industry skill competition as the carrier to promote the cultivation of innovative talents has always been an important path of the quality training plan of college students, and its significance lies in:

First, to make up for the lack of professional education to cultivate innovative ability, enhance professional integration. Professional education in colleges and universities is an educational model based on traditional education, emphasizing inheritance and development, too dogmatic, and the development of professional education should be based on innovative ability, which requires the school and professional teachers to have innovative thinking. The time and energy should be arranged to stimulate students' creative thinking, cultivate innovation ability, and stimulate the goal and direction of innovation achievement. As the verification of professional education achievement, professional skill competition can stimulate the college and teachers to send the students with innovative quality and innovation development potential to the competition field, to promote learning, to set an example and to promote the style of study. Second, enhance professional teachers and innovative class teachers' business ability and initiative. The most embarrassing thing encountered in the cultivation of innovative talents in colleges and universities is that teachers and teaching teachers do not have sufficient innovative experience, and the quality and ability of teachers themselves are important factors to promote the growth and development of innovative college students. Teachers' educational concept, knowledge structure, personality charm, innovation ability and experience are undoubtedly positively related to the cultivation of college students' innovative ability. Third, to give "one-to-one" personalized innovation training. At present, due to the constraints of teacher-student ratio, management mechanism, work efficiency and other factors in colleges and universities, only through the unified school Innovation and entrepreneurship courses or elective courses to the basic teaching of college students, and through the professional innovation competition to bring together the contestants, according to the students' creativity and personality characteristics of personalized cultivation, teaching according to their aptitude, Supplemented by knowledge of psychology, marketing, consumer behavior and so on, competition players also have PPT production, speech skills, body training, and so on, all of which require a lot of school effort. Coach and responsible teacher's time and energy for one-on-one or small class training. Therefore, it is of great significance to explore the mode of cultivating innovative talents for college students to grow up in an all-round way, taking the competition of professional innovation skills as the carrier.

From the point of view of the national college students' tea skill competition, strengthening the cultivation of college students' innovative quality is the key to cultivate innovative tea students. The competition of college students' professional skills is helpful to strengthen their professional knowledge, make use of their learning, cooperate with teams, and organize and develop their abilities. Innovation ability is not born to have, it is mainly composed of knowledge, intelligence and personality. Learning in practice, growing up in actual combat, 
"promoting growth by competition", and constantly sharpening college students' professional qualities and competitive abilities in competitions [9]. By taking part in the National college students Tea Skills competition many times, the professional learning of tea students has been greatly improved. Polarity, improve the competitiveness of employment, polish the sense of teamwork. Many colleges and universities offer appropriate group encouragement for college students to participate in professional skills competitions, while consolidating their professional knowledge and practical application ability by participating in the competitions. For the competition with professional innovation skills, individual awards and group awards are often inseparable from team cooperation and joint efforts, which is a valuable experience difficult to obtain in general professional learning and practice. Professional innovation competition (represented by tea skill competition) is the ultimate goal is to improve the comprehensive innovation ability of college students through competition, and put it into practical use. Perhaps it is not as important as scientific research competition to emphasize the great breakthrough in science and technology. Excellent selectionemphasize and attach importance to the operability, practicability and market demand of the designed products and services.

At present, there are school-level or college-level tea art teams in agricultural and forestry colleges and universities, which are managed and supported from the school level to the bottom. Fujian Agriculture and Forestry University Tea Arts team, for example, conducted auditions for tea skill competitions throughout the school. The competition included written tests on the basic knowledge of tea art, innovative tea mat design, and individual tea competition. Group tea competition and other links. At the same time, increase the leadership of teachers and guidance teachers to encourage measures. First of all, a corresponding teacher incentive policy should be introduced to reward teachers (teams) who have made outstanding contributions and achieved remarkable achievements in the cultivation and incubation of innovative practices: root According to the team and individual awardwinning situation, the tea art instructor and the leading teacher give the corresponding guidance lesson pay or transform the performance, as the priority condition of the evaluation and promotion, even the condition of participating in the evaluation and so on. Secondly, we should perfect and establish the incentive mechanism of college students' professional innovation competition, set up special fund to reward college students' innovation projects, and set up separate special guidance funds for tea art teams, which can be used to purchase tea art utensils and teachers' teaching fees. For students to give activities and awards. Third, establish professional competition training platform, integrate resources, transform into serviceoriented public competition training platform, build practice teaching, practice training, college students innovative projects And to participate in national and provincial professional disciplines competition as one, at the same time will practice teaching platform, experimental practice teaching platform, Practical teaching and practice platform, such as practice teaching network platform and competition practice teaching platform, have been added to the contents of professional competition training platform, such as the establishment of tea culture and tea art training base in Fujian Agriculture and
Forestry University. It is used to incubate and cultivate tea skill and tea culture communication.

\section{THE INTERVENTION OF PROFESSIONAL SKILLS TO PROMOTE THE ALL-ROUND DEVELOPMENT: INSPIRATION AND REFERENCE}

\section{A. People-Oriented: Respect students' personality development}

The essence of Education is "People-oriented", Respect each student's personality development. But at present, under the environment of scarce educational resources in colleges and universities, we should encourage and cultivate the innovative creative consciousness of college students. At the same time, we should set up the innovative curriculum flexibly and flexibly, and tilt the students with innovation potential to a certain extent. Allow students to gain some initiative and choice in innovative practices and courses [10]. And to give the students with creative potential the freedom to give full play to their own unique ideas in a free, democratic and open teaching atmosphere. Based on the National College students Tea skill Competition, the tea team and tea team of Fujian Agricultural and Forestry University of Fujian Province are adopted as the starting point. The culture and tea art training base gives the whole school the platform to love tea art and understand tea art independently, and gives the students the opportunity to learn tea art innovation skills by themselves, creating the tea art residence through the school level pioneering practice platform. Demonstrate the effect of tea art skills and bring students' professional skills into full play by organizing tea culture festival and other project activities. Give professional competition innovative college students precision training, classification cultivation: the first stage of general innovation courses for all college students, innovation awareness, innovative spirit to cultivate; In the second stage, aiming at college students with innovation potential and strong interest in innovation, they set up targeted and directional innovative courses, and adopted case teaching. The teaching form and practical operation in small classes enable college students to master the theoretical knowledge of innovative majors as soon as possible [11]. And "good seedlings" and "good projects" to guide, incubate and other resources tilt, this stage can grasp, to the innovative potential of college students to help huge, on the basis of Can incubate a large number of innovative teams. The third stage: set up a strong mentor team, give the innovation team the biggest skill knowledge and knowledge backup, the instructor timely correct innovation team technical problems and give correct guidance, less detours, for the entrepreneurial team escort; At the same time, the school in terms of funds, resources to give maximum support and help. The fourth stage, the competition is over, the whole school will hold the experience sharing meeting, give the incubating innovation team timely policy and work dynamics, accurately manage and track the innovation team post-competition project transformation, docking the related enterprises, and get the relevant support from the government. 


\section{B. Internalized invisible knowledge: Improving the efficiency of innovative activities}

In order to cultivate innovative competition talents in colleges and universities, we should put forward the following countermeasures to improve the efficiency of innovative activities, such as "students do not like to listen and cannot understand" in the face of the formalized phenomenon existing in the current innovative education of college students, and so on:

\section{1) Static learning accomplishment}

Static learning literacy refers to a kind of learning literacy in classroom learning, classroom library self-study and Internet learning, which is the essential ability of college students in learning and development, and it is also the basic support of forming innovation ability. It is the theoretical basis of innovative creativity and the basic skills for college students to acquire resources and self-development independently. Under the background of "big data", the static learning literacy including Internet learning can effectively and rapidly accumulate the basic knowledge of innovation activities, which has an important impact on innovation ability.

\section{2) Competitive accomplishment}

Competitive literacy, popularly speaking, is the ability to express, demonstrate, and professional knowledge that you should have before the game. Most college students do not undergo relevant training before the competition, and the direct competition is often lost because of the lack of competition literacy can not adjust the best state. But the competition type accomplishment instructor may be the discipline instruction teacher, the social etiquette specialized teacher and so on professional personage; Competition literacy can be divided into: expression literacy-language expression (explanatory notes and language adjustment training), non-verbal expression (body expression, demonstration displacement training), display type literacy (PPT production, panel production, art workers), New Media publicity training) And psychological literacy (anti-pressure ability, psychological adjustment ability, reaction speed training and communication training) and so on.

\section{Externalized professional skills: Promoting the conversion rate of employment in this major}

The proportion of agricultural graduates working in this major is less than 30 percent after graduation. As of June 2016, the proportion of graduates who participated in the tea art skills competition was as high as 90 percent (including higher education, employment, etc.). Entrepreneurship, etc.), far higher than not participating in the innovative competition students. The reason lies in, on the one hand, to strengthen professional knowledge and innovation consciousness through professional innovation competition, to stimulate college students' interest in professional subject and the motive force of innovation; On the one hand, through large-scale competitions with national and even global college students to broaden their horizons, at the same time while mastering the current advanced technology of the subject at the same time. Understand the future development trend of industry and enterprise technology. In previous national college students' tea skill competition, there are national tea enterprises leading figure, tea enterprises also pay close attention to the cultivation and incubation of tea elite talents through participating in the competition, and express the needs of enterprises. In this way to achieve benign interaction, tea graduates of the professional employment conversion rate plays a positive role.

\section{REFERENCES}

[1] Zheng Wei. Research and construction of innovative talent cultivation system in the field [J]. Mechanical design and research. 2017,33 (5): 207.

[2] Sun G.S, Liu L.G. Root specialty-The necessary path of innovative entrepreneurship education [J]. Science and technology in Chinese colleges and universities. 2017 (8): 89-91.

[3] Yang Wei. Research on cultivating college students ' scientific and technological innovation ability by relying on science and technology Competition and Innovative Experiment Plan [J]. Research on ideological and political education. 2010,26 (2): 114-116.

[4] Wang Bo, Guo J.S., Yang Y.M. Relying on science and technology competition-cultivating the innovative ability of college students majoring in civil Engineering [J]. Journal of Southeast University (philosophy and Social Sciences edition). 2012 (14). A2:261-262.

[5] Zhang X.P. On the teacher factors influencing the cultivation of college students ' creative ability [J]. Adult education in China 2016 (14): 84-88.

[6] Tao F.Y. The cultivation of college students ' innovative quality and the cultivation of innovative talents [J]. Journal of Anhui Normal University (humanities and Social Sciences). 2017,45 (4): 446-450.

[7] Chu H.F, Le Teng, kongKai. Taking skill contest as carrier-exploring innovative talent cultivation mode $[\mathrm{J}]$. Experimental technology and management. 2011 (8): 299-301.

[8] Liu F.L, Zhang.Y.Y, Liu jing, et. Challenges and Countermeasures in cultivating college students ' creative ability under the new situation [J]. Party building and ideological education in schools 2017 (2): 54-56.

[9] Liu Swen. Precision cultivation--solving the difficulty of innovative entrepreneurship education for college students [J]. Science and technology in Chinese colleges and universities. 2016 (9): 76-78.

[10] Yu Hao, Ye W.W. Internet+ on the cultivation of entrepreneurial and innovative talents $[\mathrm{J}]$. Research on higher engineering education. 2016 (3): 100-103,126. 